\title{
Compliance with guidelines is related to better local recurrence-free survival in ductal carcinoma in situ
}

\author{
MAJ de Roos", , GH de Bock², PC Baas ${ }^{3}$, L de Munck', T Wiggers' and J de Vries' \\ 'Department of Surgical Oncology, University Medical Center Groningen, University of Groningen, Hanzeplein I, PO Box 3000 I, 9700 RB Groningen, The \\ Netherlands; ${ }^{2}$ Department of Epidemiology and Bioinformatics, University Medical Center Groningen, University of Groningen, Groningen, The \\ Netherlands; ${ }^{3}$ Department of Surgery, Martini Hospital, van Swietenlaan 4, PO Box 30033, 9700 RM Groningen, The Netherlands; ${ }^{4}$ Comprehensive \\ Cancer Center North Netherlands, Waterloolaan I// 3, PO Box 330, 9700 AH Groningen, The Netherlands
}

The aim was to study the effect of compliance with guidelines on local recurrence (LR)-free survival in patients treated for ductal carcinoma in situ (DCIS). From January 1992 to December 2003, 25I consecutive patients had been treated for DCIS in two hospitals in the North Netherlands. Every case in this two-hospital sample was reviewed in retrospect for its clinical and pathological parameters. It was determined whether treatment had been carried out according to clinical guidelines, and outcomes in follow-up were assessed. In addition, all patients treated for DCIS in this region $(n=1389)$ were studied regarding clinical parameters, in order to determine whether the two-hospital sample was representative of the entire region. In the two-hospital sample, $31.4 \%(n=79)$ of the patients had not been treated according to the guidelines. Positive margins were associated with LR (hazard ratio $(H R)=4.790$, 95\% confidence interval $(\mathrm{Cl})$ 1.696-13.531). Breast-conserving surgery and deviation from the guidelines were independent predictors of $L R(H R=7.842,95 \% \mathrm{Cl} 2.126-28.926 ; H R=2.778,95 \% \mathrm{Cl} 0.982-6.78 \mathrm{I}$, respectively). Although the guidelines changed over time, time was not a significant factor in predicting LRs (HR=1.254, 95\% Cl 0.272-5.776 for time period $1992-1995$ and $\mathrm{HR}=1.976,95 \% \mathrm{Cl} 0.526-7.42$ I for time period 1996-1999). Clinical guidelines for the treatment of patients with DCIS have been developed and updated from existing literature and best evidence. Compliance with the guidelines was an independent predictor of disease-free survival. These findings support the application of guidelines in the treatment of DCIS.

British Journal of Cancer (2005) 93, I I22- | I27. doi:I0.1038/sj.bjc.66028 I5 www.bjcancer.com

Published online 18 October 2005

(c) 2005 Cancer Research UK

Keywords: breast neoplasm; ductal carcinoma in situ; clinical guidelines; breast-conserving surgery; mastectomy; local neoplasm recurrence

The main goal in the treatment of DCIS is the prevention of local recurrences (LR). Standards regarding the optimal management of patients with DCIS have been developed (Schwartz et al, 2000; Morrow et al, 2002; Mokbel 2003; Sakorafas and Farley 2003; Burstein et al, 2004). Mastectomy could be performed in cases with multiple areas of DCIS and in cases with large areas of DCIS, of a size that the lesion cannot undergo an oncologically and cosmetically acceptable excision ( $\geqslant 3 \mathrm{~cm}$ (Sakorafas and Farley, 2003); $\geqslant 4 \mathrm{~cm}$ (Mokbel, 2003)). Mastectomy could also be considered in cases with positive margins after reasonable surgical attempts of complete local excision or if it were the patient's preference and it may be indicated when breast irradiation is contraindicated (e.g. in patients who are pregnant or have collagen vascular disease). Breast-conserving surgery (BCS) could be considered where DCIS is localised and if the area $\leqslant 4 \mathrm{~cm}$. Removal of DCIS should be complete and margins should be at least $1 \mathrm{~mm}$ free of DCIS (Burstein et al, 2004). The addition of radiotherapy following local excision benefits all groups of patients with DCIS and is generally advised. Neither axillary-node

*Correspondence: Dr MAJ de Roos; E-mail: mderoos@tiscali.nl Received 13 June 2005; revised 5 September 2005; accepted 5 September 2005; published online 18 October 2005 dissection nor sentinel node biopsy (SNB) is routinely indicated. SNB could be considered in women undergoing mastectomy or in women at higher risk of occult invasive disease (patients with clinically palpable masses or areas of DCIS $>4 \mathrm{~cm}$ ). Adjuvant endocrine therapy could be considered after BCS with radiotherapy to reduce the risk of ipsilateral recurrence and contralateral disease, particularly in the case of oestrogen receptorpositive DCIS (Morrow et al, 2002; Burstein et al, 2004).

The purpose of such retrospective study is to evaluate the effect of compliance with existing clinical standards on LR-free survival in patients treated for DCIS. To estimate the effect of compliance with clinical standards in this two-hospital study, the clinical and pathological parameters for every consecutive case of DCIS, in a given period, were examined retrospectively. It was determined whether treatment had been carried out according to the standards existing at the time and the outcomes in follow-up were assessed.

\section{PATIENTS AND METHODS}

In the North Netherlands, the first guidelines for the treatment of patients with DCIS were developed in 1992 by a cooperating group of specialists in the field of breast cancer in the region (Otter, 
1992). These clinical guidelines were based on evidence from existing literature and guidelines by other groups and have been updated every 2 or 3 years. According to the above-mentioned guidelines and to those of 1994 (Otter, 1994), BCS is advised in the case of a tumour smaller than or equal to $2 \mathrm{~cm}$ and a simple mastectomy in the case of a tumour larger than $2 \mathrm{~cm}$. It is essential that BCS and mastectomy result in tumour-free margins. The 1996 guidelines (Otter, 1996) state that a complete surgical removal of all DCIS with microscopic free surgical margins is advised. Involvement of the deep margin after BCS is considered as a positive margin. A simple mastectomy is the safest way and BCS should consist of wide local excision with microscopic free margins. Adjuvant radiotherapy is optional but should not replace surgery for incomplete removal of DCIS. The 1998 (Otter, 1998) and 2000 (Otter, 2000) guidelines advise BCS with standard administration of radiotherapy for intermediately and poorly differentiated DCIS (Grades 2 and 3) and a simple mastectomy if no free margins can be achieved. If the excision is not complete in the case of well-differentiated DCIS, a wait-and-see policy is permitted if the patient is motivated, if there are no indications of hereditary breast cancer, and if mammograms can be properly reviewed. According to the 2003 guidelines (Otter, 2003), BCS and postoperative radiotherapy is advised for all subgroups. Chest wall radiation is advised if DCIS extends to the deep margin after a simple mastectomy. A sentinel node procedure could be performed in the case of tumours $\geqslant 5 \mathrm{~cm}$. Axillary lymph node dissection (ALND) has not been recommended in any guideline since 1992 and the administration of tamoxifen or other hormonal therapy has not yet been advised.

To investigate compliance with the guidelines and its effect on LR, 251 consecutive patients from two hospitals were studied. These patients had been treated for DCIS in the period January 1992 to December 2003 in the University of Groningen Medical Center (UMCG) and the Martini Hospital (MH). The UMCG is the only academic medical centre in the region and the $\mathrm{MH}$ is a large teaching hospital.

Data were retrieved retrospectively from medical charts and also from pathology and radiology reports. All analyses were performed on anonymous data. The present study is in agreement with the Dutch Law on the Conformity of Medical Treatment (WGBO). The following data were available for all patients: age, menopausal status, mode of detection, family history of breast cancer, mammographic appearance and size, fine-needle aspiration cytology, stereotactic large core needle biopsy or ultrasound guided large core needle biopsy (SCNB), treatment modalities, pathological size, pathological grade according to the European Pathologist Working Group classification (Shoker and Sloane, 1999), surgical margins and follow-up. Mammography and pathological characteristics were derived from radiology and pathology reports. If data were missing, mammography and pathological slides were re-evaluated. Surgical margins $<1 \mathrm{~mm}$ were considered to be positive. LR was defined as ipsilateral breast or chest wall recurrence of both DCIS and invasive breast cancer. The date of last follow-up was November 2004. Compliance with guidelines was stated as follows: treatment was classified as appropriate (guidelines + ) if the interventions undertaken were in agreement with the guidelines in operation at the time of treatment, whereas deviations from the guidelines were classified as inappropriate (guidelines-). Owing to changes in the guidelines, the total study period is divided into three separate time periods (1992-1995, 1996-1999 and 2000-2003).

Between January 1992 and December 2003, 1389 patients were treated for DCIS in the North Netherlands, an area of 2.1 million inhabitants. The main sources for cancer registration at the Comprehensive Cancer Center North Netherlands (CCCN) are the national computerised pathology databank (PALGA) and the hospital discharge databank to which all Dutch hospitals provide information annually on the discharge diagnoses of patients admitted. Specially trained CCCN employees prospectively register data regarding patients diagnosed with DCIS. Within the CCCN district, there is one academic medical centre, four teaching general hospitals and 12 nonteaching general hospitals.

As there are no data available in the CCCN cancer registry on tumour size and margin status, and because LR had only been registered if the recurrence consisted of invasive disease, it was not possible to evaluate all patients for treatment according to the guidelines. Therefore, clinical data concerning this population of patients treated for DCIS were used to determine whether the twohospital sample was representative for the total region of the North Netherlands.

To evaluate the effect of compliance with existing guidelines, patients were divided into an LR positive $(L R+)$ and an $L R$ negative (LR-) group. Univariate Cox regression analyses were performed for each prognostic factor separately, considering the time to the onset of LRs as the outcome. Hazard ratios (HRs) and 95\% confidence intervals (CIs) were estimated. To test the assumption of proportional hazards, an interaction term of a prognostic variable and a time-dependent covariate were added to each separate model (Klein and Moeschberger, 2003). A significant effect of that interaction term denotes the presence of a timedependent effect and thus a violation of the proportional hazards assumption. As a control for unmeasured differences in the study period, due to changes in guidelines over time, we added the study period as a factor in the multivariate Cox regression analysis. Subsequently multivariate Cox regression analyses were performed. The elimination of variables in a stepwise manner identified the statistically significant predictors. LR-free survival was analysed using Kaplan-Meier survival analysis and the logrank test. Patients were censored if they had died or otherwise been lost to follow-up. A $P$-value of 0.05 was considered as significant. All analyses were performed with program SPSS version 12.01 .

\section{RESULTS}

Clinicopathological characteristics of patients in the two-hospital sample are summarised in Table 1 . The median age of the total study population was 57 years (range $32-85$ years). In all, $49 \%$ $(n=122)$ of all cases were detected by the Dutch Breast Cancer Screening Programme. Nearly one-third of the women $(n=79)$ had not been treated according to the guidelines operating in the year of treatment. A total of 18 patients had positive margins after final surgery.

BCS (HR $=10.328,95 \%$ CI 2.907-36.693), positive margins $(\mathrm{HR}=4.790,95 \% \mathrm{CI} 1.696-13.531)$ and inappropriate treatment (guidelines- $(\mathrm{HR}=4.339,95 \% \mathrm{CI} 1.695-11.18)$ ) were all characteristics associated with LR in univariate analysis (Table 1). There was no violation of the assumption of proportional hazards regarding the outcome and any prognostic factor (unpublished data). In Table 2, the independent predictors of LR after treatment of DCIS are shown: BCS without radiotherapy (HR $=7.842,95 \% \mathrm{CI}$ 2.126-28.926) and deviation from the guidelines ( $\mathrm{HR}=2.778,95 \%$ CI $0.982-6.781$ ). Although the guidelines changed with time, time was not a significant factor in the Cox analysis $(\mathrm{HR}=1.254,95 \%$ CI $0.272-5.776$ for study period $1992-1995$ and $\mathrm{HR}=1.976,95 \%$ CI $0.526-7.421$ for study period 1996-1999).

The median follow-up was 43 months (mean 49, range 10-120 months). Figure 1A shows that LR-free survival was better in patients who had been treated according to the guidelines than in patients who had been treated inappropriately (log rank 10.41, $P=0.001)$. The 5-year LR-free survival in patients treated with BCS, was $91 \%$ in patients who had been treated according to the guidelines and $73 \%$ in patients who had not been treated so (log rank $4.77, P=0.029$; Figure $1 \mathrm{~B}$ ). 
Table I Clinico-pathological characteristics of patients of the two-hospital sample and local recurrence (Cox's regression, univariate analysis)

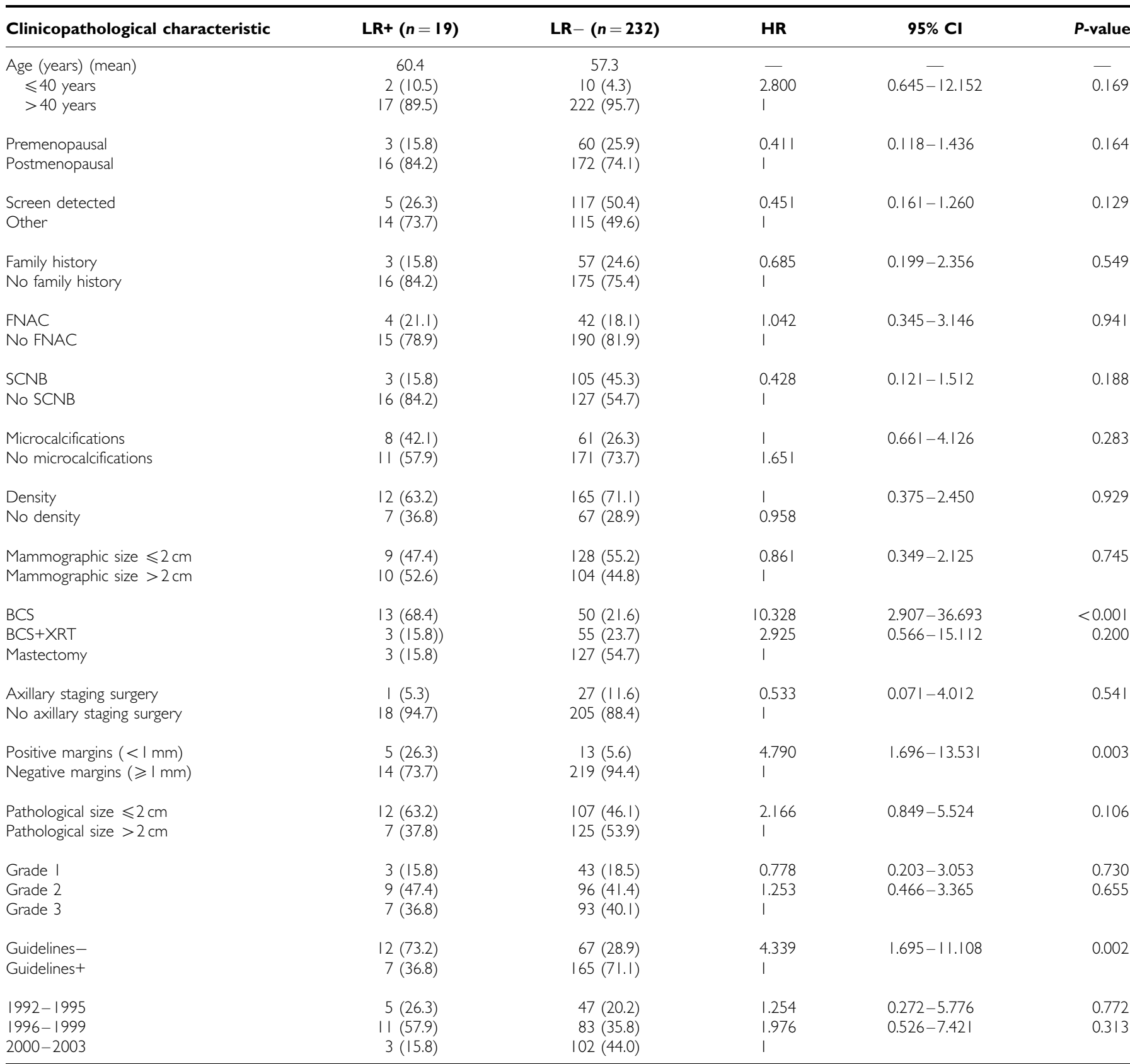

$\mathrm{LR}+=$ local recurrence; age is depicted as the median value; $\mathrm{HR}=$ hazard ratio; $\mathrm{Cl}=$ confidence interval; $\mathrm{FNAC}=$ fine-needle aspiration cytology; $\mathrm{SCNB}=$ stereotactic large core needle biopsy; $\quad B C S=$ breast-conserving surgery; $\quad B C S+X R T=$ breast-conserving surgery and radiotherapy; pathological grade according to EPWG classification; guidelines $+=$ treatment according to $\mathrm{CCCN}$ guidelines.

In Table 3, clinical data of patients treated in the two-hospital sample are compared with data from the entire population of patients in the North Netherlands. Patients in the two-hospital sample had undergone fewer axillary staging procedures than patients in the total region $\left(\chi^{2}=32.64 ; P<0.001\right)$. Information on surgical management with regard to the entire population of patients in the North Netherlands was available for 1221 of the 1389 women involved: less than half of the women $(n=525,43.0 \%)$ had BCS. Information on axillary surgical management was also available for 1221 of the 1389 women involved: 299 women (24.5\%) had ALND or SNB.

Of all patients with LRs $(n=19)$ in the two-hospital sample, seven patients had been treated according to the guidelines and 12 patients had been treated inappropriately. Of these 12 patients, five had positive margins after final surgery, four had not received adjuvant radiotherapy after local excision, two patients had not undergone mastectomy, although their tumours were larger than two centimetres, and one patient had undergone ALND.

\section{DISCUSSION}

Clinical guidelines reflect optimal management according to existing views and literature, and have been introduced to reduce inappropriate practice and to improve the quality of care (Lomas et al, 1989; Grimshaw and Russell, 1993; Mann, 1996). In the North 
Table 2 Predictors of local recurrence (Cox's regression, multivariate analysis)

\begin{tabular}{lccc}
\hline Predictors of local recurrence & HR & $\mathbf{9 5 \%} \mathbf{~ C l}$ & $\boldsymbol{P}$-value \\
\hline BCS & 7.842 & $2.126-28.926$ & 0.002 \\
BCS+XRT & 2.432 & $0.471-12.552$ & 0.085 \\
Mastectomy & I & & \\
Deviation from the guidelines & 2.778 & $0.982-6.781$ & 0.041 \\
Compliance with the guidelines & $\mathrm{I}$ & & \\
\hline
\end{tabular}

$\mathrm{BCS}=$ breast-conserving surgery; $\mathrm{HR}=$ hazard ratio; $\mathrm{Cl}=$ confidence interval; $\mathrm{BCS}+\mathrm{XRT}=$ breast-conserving surgery and radiotherapy. Regression analysis by elimination of variables in a stepwise manner. As a control for unmeasured differences in the study period, due to changes in guidelines over time, the study period was added as a factor in the analysis.
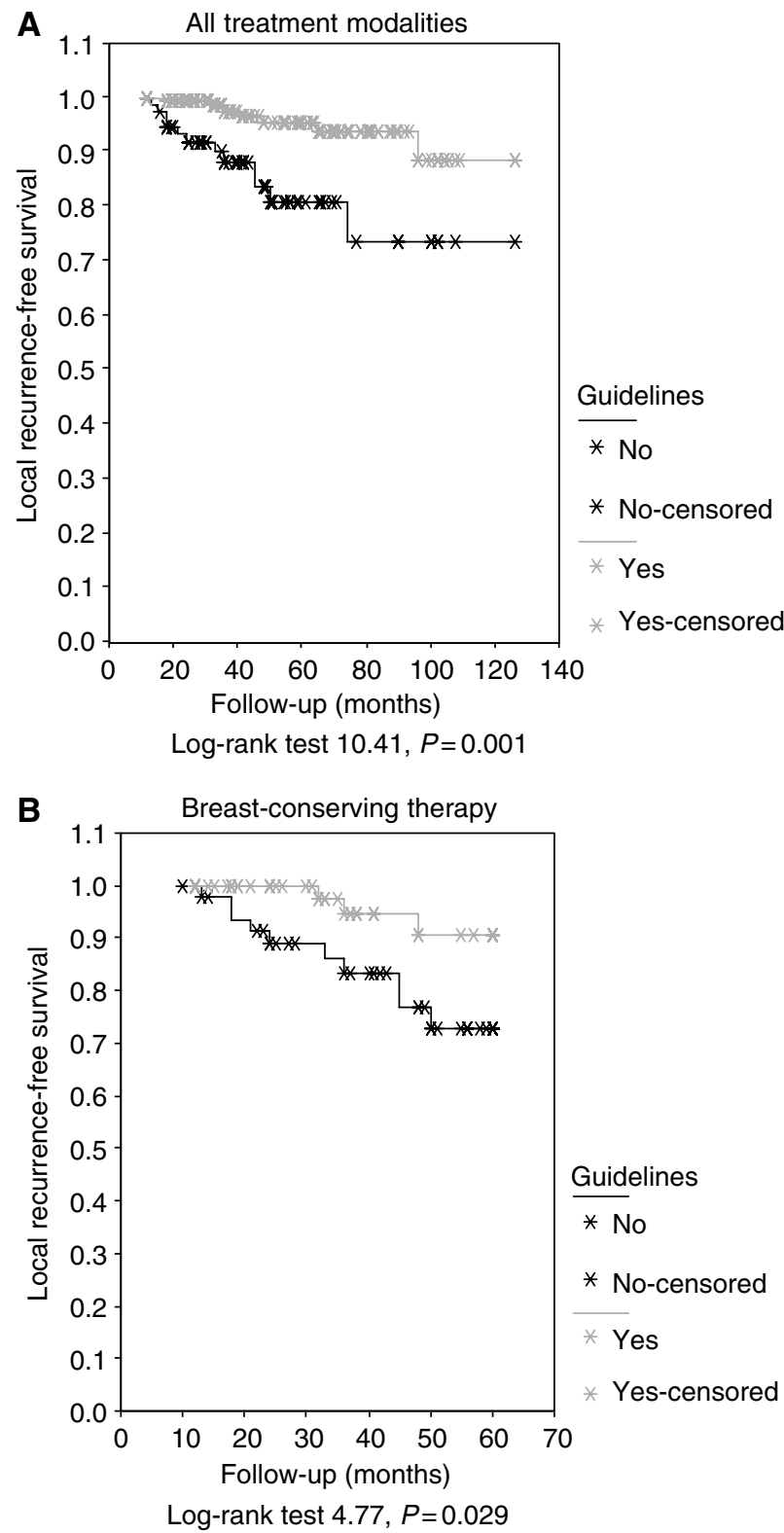

Figure I (A) Local recurrence-free survival in all patients who were treated according to the guidelines (guidelines + ) and in all patients who were not treated according to the guidelines (guidelines-). (B) The 5-year local recurrence-free survival after BCS in patients who were treated according to the guidelines (guidelines + ) and in patients who were not treated according to the guidelines (guidelines-).
Table 3 Clinical characteristics of patients of the entire region of the North Netherlands (CCCN population) and the two-hospital sample

\begin{tabular}{|c|c|c|c|c|}
\hline $\begin{array}{l}\text { Clinical } \\
\text { characteristics }\end{array}$ & $\begin{array}{c}\text { CCCN } \\
\text { population } \\
(n=1389)\end{array}$ & $\begin{array}{c}\text { Two-hospital } \\
\text { sample }(n=251)\end{array}$ & $\chi^{2}$ & $P$-value \\
\hline $\begin{array}{l}\text { Mean age (years) } \\
\text { (range) }\end{array}$ & $60(22-98)$ & $57(32-85)$ & - & - \\
\hline \multicolumn{5}{|l|}{ Screen detected } \\
\hline Yes & $625(45.0)$ & $122(48.6)$ & 1.12 & 0.291 \\
\hline No & $764(55.0)$ & $129(51.4)$ & & \\
\hline \multicolumn{5}{|l|}{ Surgery } \\
\hline BCS & $525(43.0)$ & 121 (48.2) & 2.30 & 0.130 \\
\hline Mastectomy & $696(57.0)$ & | 30 (5|.8) & & \\
\hline Unknown & 168 & 0 & & \\
\hline \multicolumn{5}{|l|}{ Axillary surgery } \\
\hline ALND & $240(19.7)$ & $12(4.8)$ & 32.64 & $<0.001$ \\
\hline SNB & $59(4.8)$ & $16(6.4)$ & & \\
\hline No axillary & $922(75.5)$ & $223(88.8)$ & & \\
\hline \multicolumn{5}{|l|}{ Surgery } \\
\hline Unknown & 168 & 0 & & \\
\hline \multicolumn{5}{|l|}{ Radiotherapy } \\
\hline Yes & $292(55.6)$ & $58(48.0)$ & 2.34 & 0.126 \\
\hline No & $233(44.4)$ & $63(52.0)$ & & \\
\hline
\end{tabular}

Netherlands, the first guidelines for the treatment of patients with DCIS were developed in 1992 and subsequently they have been updated every 2 or 3 years. The present study was undertaken to investigate the effect of compliance with the existing guidelines on LR-free survival, and it clearly demonstrates that treatment according to these guidelines leads to a better outcome.

Owing to the change of guidelines over time, study period can be considered as a proxy for the nature of guidelines. However, since the study period is not a significant factor in the Cox analysis, the present study should not be considered to be a validation of the guidelines. In addition, the LR rate did not improve over time, since the events and follow-up of patients treated, especially in the third study period, are insufficient to show differences. Compliance with the guidelines is the only predictive factor, whereas there is no indicative effect of the nature of the guidelines on outcome. Other well-known risk factors for LR have been included in the study and they did not prove to be related with LR. Therefore, it can be concluded that there were no other factors in the group not treated according to the guidelines that could have led to their poorer outcome.

Physicians who carry out the treatment according to the guidelines often take a special interest in breast cancer, and they usually work in multidisciplinary teams. It is most likely that the positive effect of the guidelines on disease-free survival could be explained by this practice. It has already been demonstrated that surgeon workload is associated with survival from breast cancer (Stefoski Mikeljevic et al, 2003). If physicians are exposed to a high case volume of patients with DCIS, and if they follow the guidelines and work in multidisciplinary teams, it is plausible that they will be aware of the existing literature covering the whole process of diagnostic work-up, treatment and follow-up. This practice should result in better quality of care and an improvement in outcome.

Few data exist regarding outcome differences associated with deviation from clinical guidelines. Institutional validation of breast cancer treatment guidelines in Florida reported no effect from compliance with the guidelines on 5-year survival, but there was a 
significant reduction in the costs if the guidelines were followed (Minter et al, 2001). The above-mentioned study lacked statistical power to detect any small difference in overall 5-year survival between the groups. Furthermore, LR-free survival was not studied and patients with DCIS were excluded. In the systemic adjuvant treatment of patients with breast cancer, Olivotto et al (1994) demonstrated that improvements in disease-free survival and overall survival, noted during the time period of guideline implementation, were similar to those observed in clinical trials. The causality could not be demonstrated, but it was suggested that the improvements in disease-free survival were the result of operating within the guidelines.

Deviation from the guidelines automatically results in under- or overtreatment of patients. If patients have been undertreated, their prognosis is thought to be worse than that of patients who have been treated appropriately. Overtreatment leads to unnecessary procedures and overshooting the mark. The inappropriately treated population in the present study $(n=79)$ consisted of 49 patients $(62 \%)$ who had been undertreated, and 30 patients $(38 \%)$ who had been overtreated. Under- or overtreatment was not associated with LR (unpublished data).

In the 12-year period 1992-2003, the guidelines of treatment of patients with DCIS have evolved, along with new evidence from studies and trials on this disease. If the most recent CCCN guidelines (Table 4) are compared with other guidelines (Rutgers et al, 2001, Olivotto et al, 2001; Morrow et al, 2002; The Association of Breast Surgery, 2005), conference reports (Schwartz et al, 2000; Senn et al, 2003) and review articles (Mokbel, 2003; Sakorafas and Farley, 2003; Burstein et al, 2004), there is a high degree of consensus between all these documents. Chest wall radiation for a positive margin after simple mastectomy is not mentioned in other guidelines. The administration of tamoxifen after BCS with radiotherapy (in oestrogen-receptor-positive patients) has so far not been issued, and this policy has not been followed in the two-hospital sample either. The addition of tamoxifen to the guidelines might help reduce the incidence of LRs.

The proportion of patients in the two-hospital sample who had been treated by simple mastectomy (52\%) was similar to the proportion of patients in the entire region of the North Netherlands (57\%). This percentage approximates the reports from earlier periods in the southeast Netherlands (1984-1989, 53\%; Voogd et al, 2000) and from North Carolina (1990-2000, 52\%; Kotwall et al, 2003), but is much higher than that reported in recent studies from California, Australia and Geneva (38, 24 and $22 \%$, respectively; Morris et al, 2000; Verkooijen et al, 2002; Kricker and Armstrong, 2004). This indicates that mastectomy has played a dominant role in the treatment of patients with DCIS in the North Netherlands during the study period when compared with other studies. Axillary lymph node staging procedures (including sampling and SNB) had been performed on 299 (25\%) out of 1221 patients (in 168 patients it was unknown whether axillary surgery had been performed). While this percentage was higher than in the subgroup of the two-hospital

Table 4 Summary of recent clinical guidelines and recommendations in the management of DCIS

\begin{tabular}{|c|c|c|c|c|c|}
\hline Guidelines & BCS & Mastectomy & Axillary staging & Radiotherapy & Hormonal therapy \\
\hline $\begin{array}{l}\text { EUSOMA } \\
\text { (Rutgers et al, } \\
2001 \text { ) }\end{array}$ & $\begin{array}{l}\text { BCS is advised in the } \\
\text { case of small areas of } \\
\text { DCIS }(<3 \mathrm{~cm}) \\
\text { Condition: free margins }\end{array}$ & $\begin{array}{l}\text { Mastectomy is advised in the } \\
\text { case of large areas of DCIS } \\
(>3 \mathrm{~cm}) \\
\text { Mastectomy is advised in the } \\
\text { case of persistent positive } \\
\text { margins after BCS }\end{array}$ & $\begin{array}{l}\text { Axillary staging is not } \\
\text { recommended }\end{array}$ & $\begin{array}{l}\text { Whole-breast irradiation is } \\
\text { optional after BCS }\end{array}$ & - \\
\hline
\end{tabular}

\begin{tabular}{|c|c|c|c|c|c|}
\hline $\begin{array}{l}\text { SCCPG } \\
\text { (Olivotto et al, } \\
200 I \text { ) }\end{array}$ & $\begin{array}{l}\text { BCS is advised in the } \\
\text { case of small areas of } \\
\text { DCIS } \\
\text { Conditions: cosmetically } \\
\text { acceptable and free } \\
\text { margins }\end{array}$ & $\begin{array}{l}\text { Mastectomy is advised in the } \\
\text { case of large or diffuse areas } \\
\text { of DCIS } \\
\text { Mastectomy is advised in the } \\
\text { case of persistent positive } \\
\text { margins after BCS }\end{array}$ & $\begin{array}{l}\text { Axillary staging is not } \\
\text { recommended }\end{array}$ & $\begin{array}{l}\text { Whole-breast irradiation is } \\
\text { advised after BCS }\end{array}$ & $\begin{array}{l}\text { Hormonal therapy is } \\
\text { optional after BCS } \\
\text { and XRT }\end{array}$ \\
\hline \multirow{2}{*}{$\begin{array}{l}\text { ACR } \\
\text { ACS } \\
\text { CAP } \\
\text { SSO } \\
\text { (Morrow et al, } \\
\text { 2002) }\end{array}$} & $\begin{array}{l}\text { BCS is advised in the } \\
\text { case of localised DCIS } \\
\text { and extent } \leqslant 4 \mathrm{~cm}\end{array}$ & $\begin{array}{l}\text { Mastectomy is advised in the } \\
\text { case of multifocal and diffuse } \\
\text { DCIS }\end{array}$ & $\begin{array}{l}\text { SNB or level I ALND is } \\
\text { advised in the case of large } \\
\text { areas of DCIS requiring } \\
\text { mastectomy }\end{array}$ & $\begin{array}{l}\text { Whole-breast irradiation is } \\
\text { advised after BCS }\end{array}$ & $\begin{array}{l}\text { Hormonal therapy is } \\
\text { optional after BCS } \\
\text { and XRT }\end{array}$ \\
\hline & $\begin{array}{l}\text { Conditions: cosmetically } \\
\text { acceptable and free } \\
\text { margins }\end{array}$ & $\begin{array}{l}\text { Mastectomy is advised in the } \\
\text { case of persistent positive } \\
\text { margins after BCS }\end{array}$ & & & \\
\hline $\begin{array}{l}\text { CCCN } \\
\text { (Otter, 2003) }\end{array}$ & $\begin{array}{l}\text { BCS has the preference } \\
\text { overmastectomy } \\
\text { Conditions: cosmetically } \\
\text { acceptable and free } \\
\text { margins }\end{array}$ & $\begin{array}{l}\text { Mastectomy is advised in the } \\
\text { case of persistent positive } \\
\text { margins after BCS }\end{array}$ & $\begin{array}{l}\text { SNB is advised in the case } \\
\text { of large areas of DCIS } \\
(\geqslant 5 \mathrm{~cm})\end{array}$ & $\begin{array}{l}\text { Whole-breast irradiation is } \\
\text { advised after BCS } \\
\text { Chest wall irradiation is advised } \\
\text { in the case of a positive } \\
\text { margin after mastectomy }\end{array}$ & $\begin{array}{l}\text { Hormonal therapy is } \\
\text { not recommended }\end{array}$ \\
\hline $\begin{array}{l}\text { BASO (The } \\
\text { Association of } \\
\text { Breast Surgery, } \\
\text { 2005) }\end{array}$ & - & $\begin{array}{l}\text { Mastectomy is advised in the } \\
\text { case of extensive } \\
\text { microcalcifications on } \\
\text { mammography }\end{array}$ & $\begin{array}{l}\text { SNB is advised in the case } \\
\text { of extensive tumour, high } \\
\text { grade, palpable mass or mass } \\
\text { on mammography }\end{array}$ & $\begin{array}{l}\text { Whole-breast irradiation is } \\
\text { advised after BCS }\end{array}$ & - \\
\hline
\end{tabular}

$\mathrm{BCS}=$ breast-conserving surgery; EUSOMA = European Society of Mastology; condition = all the conditions must be met in order to carry out BCS; SCCPG = Steering Committee on Clinical Practice Guidelines for the Care and Treatment of Breast cancer; ACR = American College of Radiology; SNB = sentinel node biopsy; $A C S=$ American College of Surgeons; ALND = axillary lymph node dissection; CAP = College of American Pathology; SSO = Society of Oncology; CCCN= Comprehensive Cancer Centre North Netherlands; BASO = British Association of Surgical Oncology. 
sample $(11 \%)$, indicating that this percentage is rather high and could be brought down, it is comparable with data from parts of Australia (18\%; Kricker and Armstrong, 2004) and the US SEER registries (15-34\%; Baxter et al, 2004), indicating that, at the same time, it is acceptable to compare the percentages of our cohort of patients with DCIS to those of other large cohorts elsewhere.

Outcome in patients with DCIS was not measured as overall survival, but as LR-free survival because, in the follow-up period of the study, only two patients died. It was not possible to establish whether the two-hospital population under study was representative of the whole region with regard to pathological size and margin status after final surgery, or with regard to the number of
LRs. This might yield bias in the sense that other factors associated with LR-free survival could have been identified had data of the entire population of patients of the North Netherlands been known.

In conclusion, the introduction and update of guidelines for the treatment of patients with DCIS in the CCCN region resulted in a compliance rate of $68.8 \%$ of the patients in the two-hospital sample and the two-hospital sample was representative for the whole region. Compliance with the guidelines was an independent predictor of disease-free survival. These data support the application of guidelines in the treatment of DCIS and they emphasise the importance of audit to assess whether guidelines are being followed.

\section{REFERENCES}

Baxter NN, Virnig BA, Durham SB, Tuttle TM (2004) Trends in the treatment of ductal carcinoma in situ of the breast. J Natl Cancer Inst 96: $443-448$

Burstein HJ, Polyak K, Wong JS, Lester SC, Kaelin CM (2004) Ductal carcinoma in situ of the breast. $N$ Engl J Med 350: 1430-1441

Grimshaw JM, Russell IT (1993) Effect of clinical guidelines on medical practice: a systematic review of rigorous evaluations. Lancet 342: $1317-$ 1322

Klein JP, Moeschberger ML (2003) Survival Analysis: Techniques for Censored and Truncated Data, 2nd edn. New York: Springer-Verlag

Kotwall C, Brinker C, Covington D, Hall T, Hamann MS, Maxwell JG, Stiles A, Weiss A (2003) Local and national trends over a decade in the surgical treatment of ductal carcinoma in situ. Am J Surg 186: $723-729$

Kricker A, Armstrong B (2004) Surgery and outcomes of ductal carcinoma in situ of the breast: a population-based study in Australia. Eur J Cancer 40: $2396-2402$

Lomas J, Anderson GM, Domnick-Pierre K, Vayda E, Enkin MW, Hannah WJ (1989) Do practice guidelines guide practice? The effect of a consensus statement on the practice of physicians. $N$ Engl J Med 321: $1306-1311$

Mann T (1996) Clinical Guidelines: Using Clinical Guidelines to Improve Patient Care within the NHS. London: NHS Executive

Minter RM, Spengler KK, Topping DP, Flug R, Copeland EM, Lind DS (2001) Institutional validation of breast cancer treatment guidelines. J Surg Res 100: 106-109

Mokbel K (2003) Towards optimal management of ductal carcinoma in situ of the breast. Eur J Surg Oncol 29: 191-197

Morris CR, Cohen R, Schlag R, Wright WE (2000) Increasing trends in the use of breast conserving surgery in California. Am J Public Health 90: $281-284$

Morrow M, Strom AE, Bassett LW, Dershaw DD, Fowble B, Giuliano A, Harris JR, O'Malley F, Schnitt SJ, Singletary SE, Winchester DP, American College of Radiology; American College of Surgeons; Society of Surgical Oncology; College of American Pathology (2002) Standard for the management of ductal carcinoma in situ of the breast. CA Cancer J Clin 52: 256-276

Olivotto I, Levine $\mathrm{M}$, for the steering committee on clinical practice guidelines for the care and treatment of breast cancer (2001) Clinical practice guidelines for the care and treatment of breast cancer: the management of ductal carcinoma in situ (summary of the 2001 update). CMAJ 165: $912-913$

Olivotto IA, Bajdik CD, Plenderleith IH, Coppin CM, Gelmon KA, Jackson SM, Ragaz J, Wilson KS, Worth A (1994) Adjuvant systemic therapy and survival after breast cancer. $N$ Engl J Med 330: 805-810
Otter R (ed) (1992) Richtlijnen voor diagnostiek en behandeling van premaligne en maligne aandoeningen in de IKN-regio 1992 p 290 Groningen: IKN; ISBN 90-74114-03-2

Otter R (ed) (1994) Richtlijnen voor diagnostiek en behandeling van premaligne en maligne aandoeningen in de IKN-regio 1994 pp 318-319. Groningen: IKN; ISBN 90-74114-06-7

Otter R (ed) (1996) Richtlijnen voor diagnostiek en behandeling van premaligne en maligne aandoeningen in de IKN-regio $1996 \mathrm{p} 337$ Groningen: IKN; ISBN 90-74114-06-7

Otter R (ed) (1998) Richtlijnen voor diagnostiek en behandeling van premaligne en maligne aandoeningen in de IKN-regio 1998 pp 330-331. Groningen: IKN; ISBN 90-74114-06-7

Otter R (ed) (2000) Richtlijnen voor diagnostiek en behandeling van premaligne en maligne aandoeningen in de IKN-regio 2000 pp 329-330. Groningen: IKN; ISBN 90-74114-20-2

Otter R (ed) (2003) Richtlijnen voor diagnostiek en behandeling van premaligne en maligne aandoeningen in de IKN-regio 2003 pp 338-339. Groningen: IKN; ISBN 90-74114-25-3

Rutgers EJTh, for the EUSOMA Consensus Group (2001) Quality control in the locoregional treatment of breast cancer. Eur J Cancer 37: 447-453

Sakorafas GH, Farley DR (2003) Optimal management of ductal carcinoma in situ of the breast. Surg Oncol 12: 221-240

Schwartz GF, Solin LJ, Olivotto IA, Ernster VI, Pressman PI (2000) Consensus conference on the treatment of in situ ductal carcinoma of the breast, April 22-25, 1999. Cancer 88: $946-954$

Senn HJ, Thürlimann B, Godhirsch A, Wood WC, Gelber RD, Coates AS (2003) Comments on the St Gallen consensus 2003 on the primary therapy of early breast cancer. Breast 12: $569-582$

Shoker BS, Sloane JP (1999) DCIS grading schemes and implications. Histopathology 35: 393-400

Stefoski Mikeljevic J, Haward RA, Johnston C, Sainsbury R, Forman D (2003) Surgeon workload and survival for breast cancer. Br J Cancer 89: $487-491$

The Association of Breast Surgery@BASO, Royal College of Surgeons (2005) Guidelines for the management of symptomatic breast disease. Eur J Surg Oncol 31: S1-S21

Verkooijen HM, Fioretta G, de W olf C, Vlastos G, Kurtz J, Borisch B, Schafer P, Spiliopoulos A, Sappino AP, Renella R, Pittet B, Schmid De Gruneck J, Wespi Y, Neyroud-Caspar I, Bouchardy C (2002) Management of women with ductal carcinoma in situ of the breast: a populationbased study. Ann Oncol 13: 1236-1245

Voogd AC, Crommelin MA, Repelaer van Driel OJ, Nolthenius-Puylaart MC, van der Heijden LH, Coebergh JW (2000) Trends in incidence and treatment of ductal carcinoma in situ of the breast in southeast Netherlands. Ned Tijdschr Geneeskd 14: 659-663 